\title{
MISERICORDIA, AMOR A LOS POBRES, COLABORACIÓN EN LA CONSTRUCCIÓN DE LA “CASA COMÚN"
}

Nuestro camino en la vida a la luz del magisterio del Papa Francisco

Fernando Chica Arellano

Roma

\section{RESUMEN / ABSTRACT}

El presente artículo aborda los temas de la misericordia, el amor a los pobres y la colaboración en la construcción del mundo que nos rodea, o "casa común", a la luz de las enseñanzas del Papa Francisco, concretamente en su Carta encíclica Laudato si'y otros documentos como Lumen fidei. Dos imágenes suyas sirven de punto de partida: plantar un árbol y abrir una puerta. La opción preferencial por los pobres es el denominador común, en este caso en relación con la ecología y la protección del medio ambiente. La contaminación, el cambio climático y la "cultura del descarte" afectan en primer lugar a los más necesitados. El Papa profundiza en las raíces del problema y propone algunos principios pedagógicos, a la luz del "Evangelio de la creación", que se discuten en detalle en este artículo. Se concluye con la llamada a la "conversión ecológica".

The present article deals with the issues of mercy, love for the poor, and the necessary collaboration to construct the surrounding world, our "common house", on the basis of Pope Francis's teaching, namely his Encyclical Laudato si' and other documents such as Lumen fidei. Two of his images are taken as the starting point: planting a tree and opening a door. The preferential option for the poor is the common denominator, in this case as related to ecology and 
the protection of the environment. Pollution, climatic change, and what the Pope calls "the disregarding culture" mostly affect those most needed. Pope Francis delves into the roots of the problem and proposes some pedagogical principles in the light of the "Gospel of creation", which are discussed in detail in this article. The conclusion is an appeal to "ecological conversion".

\section{O. INTRODUCCIÓN}

Quisiera comenzar esta reflexión, que os invito a que sea un auténtico diálogo fraterno, con una premisa que enmarca el momento eclesial que estamos viviendo y que recoge muy bien el estilo pastoral del Papa Francisco: acompañar la reflexión teórica con la acción concreta y el compromiso ${ }^{1}$.

Como pórtico de mis palabras, desearia referirme a dos acontecimientos recientes que se han desarrollado lejos de nuestra ciudad pero que hemos presenciado gracias a los medios de comunicación, que nos llevan a la calidez del hogar las noticias más remotas. Se trata del reciente viaje del Sumo Pontífice a África central y de la apertura del Año Jubilar de la misericordia. Geográficamente, el Sucesor del apóstol Pedro se ha traslado de Roma, corazón de la cristiandad, al centro de la pobreza en África como heraldo de un mensaje que abre al hombre horizontes de esperanza. Y ha vuelto a Roma, la Ciudad Eterna, para concretar que el progreso de la humanidad pasa por el abandono de la violencia y el retorno a Dios, que es Padre de infinita clemencia. Un hilo conductor ha movido este desplazamiento: el anuncio del Evangelio, hoy, más que nunca, Evangelio de la misericordia.

El Evangelio no es una realidad que flota en el vacío sino que se encarna en las coordenadas de tiempo y espacio en las que vivimos. La Iglesia brinda la misericordia, auténtico rostro de Dios, como bálsamo a una sociedad herida. Y el gesto del Papa de viajar a África en estos momentos quiere reclamar la atención de todos, especialmente del Primer Mundo, para que no se olvide la tragedia que viven tantas personas en los países más pobres.

1 Conferencia pronunciada en la Universidad de Sevilla, promovida por el S.A.R.U.S., el 5 de febrero de 2016. 
El creyente siempre debe auscultar la realidad y buscar pautas de reflexión y de comportamiento para transformarla según los valores del Evangelio. Como nos dice el Concilio Vaticano II, del que el pasado 8 de diciembre de 2015 festejábamos los 50 años de su clausura, la Iglesia promueve todo lo que es humano, ya que ningún problema del hombre le es ajeno. Antes bien, ella vibra con las problemáticas que anidan en nuestro corazón, pues "es escuela del mejor humanismo" y nos presenta a Jesucristo como modelo de "hombre perfecto" y fuente de luz para que la persona pueda entender cabalmente sus aspiraciones, anhelos y preocupaciones (cf. GS 41).

\subsection{Dos iniciativas simbólicas del viaje del Santo Padre Francisco a África}

Una imagen habla más que mil palabras, por eso me gustaría evocar dos iconos extraídos de la vida ordinaria y que adquieren la categoría de símbolo para la acción pastoral en nuestros días: plantar un árbol y abrir una puerta.

\section{- Plantar un árbol}

Un signo universal y arraigado en las tradiciones africanas como es plantar un árbol fue el gesto llevado a cabo por el Papa Francisco durante la etapa inicial de su primer viaje en el inmenso continente africano, en una Nairobi sobre la cual poco después, mientras llegaba la noche, cayó una densa lluvia que mojó con abundancia la planta que acababan de sembrar. En Kenia esta costumbre, fácilmente comprensible, está difundida sobre todo entre los jóvenes que culminan un ciclo escolar, como símbolo de apertura hacia el futuro. Esta es una constante en el pensamiento del actual Pontífice: la mirada hacia el porvenir sin pesimismo, la confianza en Dios como camino para afrontar la vida. Podríamos tomar nota de ella, para llevarla a la práctica en nuestra vida ${ }^{2}$.

2 "De camino hacia esta sala me han invitado a plantar un árbol en el parque del Centro de las Naciones Unidas. Quise aceptar este gesto simbólico y sencillo, cargado de significado en tantas culturas. Plantar unárbol es, en primerainstancia, unainvitación 
Así, plantando un arbolito destinado a las futuras generaciones, un elocuente signo de esperanza, Su Santidad quiso expresar la confianza en Dios para que sostenga los esfuerzos de los que trabajan por "cultivar una sociedad solidaria, justa y pacífica", en Kenia y en toda África. El Papa escogió precisamente este país de África, Kenia, para resaltar el proceso democrático emprendido con el objetivo de construir una sociedad multiétnica, justa e inclusiva, en una nación que el Obispo de Roma definió ante todo como joven, y que, por lo tanto, debe saber invertir en los jóvenes ${ }^{3}$. En un videomensaje previo a su viaje, el Papa designó a los jóvenes africanos como el "recurso más grande y nuestra esperanza más prometedora para un futuro de solidaridad, paz y progreso" 4 .

a seguir luchando contra fenómenos como la deforestación y la desertificación. Nos recuerda la importancia de tutelar y administrar responsablemente aquellos "pulmones del planeta repletos de biodiversidad [como bien lo podemos apreciar en este continente con] la cuenca fluvial del Congo", lugar esencial "para la totalidad del planeta y para el futuro de la humanidad". Por eso es siempre apreciada y alentada "la tarea de organismos internacionales y de organizaciones de la sociedad civil que sensibilizan a las poblaciones y cooperan criticamente, también utilizando legitimos mecanismos de presión, para que cada gobierno cumpla con su propio e indelegable deber de preservar el ambiente y los recursos naturales de su pais, sin venderse a intereses espurios locales o internacionales" (Carta enc. Laudato si', 38). A su vez, plantar un árbol nos provoca a seguir confiando, esperando y especialmente comprometiendo nuestras manos para revertir todas las situaciones de injusticia y deterioro que hoy padecemos": Francisco, Discurso en la visita a la oficina de las Naciones Unidas en Nairobi (UNON). Nairobi (26 noviembre de 2015): L'Osservatore Romano, ed. semanal en lengua española (4 de diciembre de 2015), p. 3.

3 "Kenia es una nación joven y vibrante, una sociedad de gran diversidad, que desempeña un papel significativo en la región. En muchos aspectos, su experiencia de dar forma a una democracia es compartida por muchas otras naciones africanas. Al igual que Kenia, ellas también están trabajando para construir, sobre las bases sólidas del respeto mutuo, el diálogo y la cooperación, una sociedad multiétnica que sea verdaderamente armoniosa, justa e inclusiva. La suya es también una nación de jóvenes. Espero encontrarme con muchos de ellos estos días, hablar con ellos y poder alentar sus esperanzas y aspiraciones para el futuro. Los jóvenes son la riqueza más valiosa de una nación. Protegerlos, invertir en ellos y tenderles una mano es la mejor manera que tenemos para garantizarles un futuro digno de la sabiduria y de los valores espirituales apreciados por sus mayores, valores que son el corazón y el alma de un pueblo": Francisco, Discurso en el encuentro con las autoridades de Kenia y el Cuerpo diplomático. State House. Nairobi (25 noviembre de 2015): L'Osservatore Romano, ed. semanal en lengua española (27 de noviembre de 2015), p. 10.

4 Videomensaje del Santo Padre Francisco en visperas de su Viaje apostólico a Kenia y Uganda. 25-30 noviembre de 2015: L'Osservatore Romano, ed. semanal en lengua española (27 de noviembre de 2015), p. 16. 
Pero también caracterizan a Kenia la belleza y la abundancia de los recursos naturales, aspectos que llevaron al Pontífice a hacer mención de la grave crisis ambiental, a pocos dias de la Conferencia de París sobre el cambio climático ${ }^{5}$, en la que la Santa Sede estaría representada por una Delegación encabezada por el Secretario de Estado, Cardenal Pietro Parolin, que acompañaba al Papa en su visita pastoral al continente africano, y que antes de su conclusión volvió a Europa para hacerse presente en ese significativo foro internacional parisino ${ }^{6}$.

5 La XXI Conferencia Internacional sobre Cambio Climático o XXI Conferencia de las Partes y la XI Conferencia de las Partes en calidad de reunión de las Partes en el Protocolo de Kyoto (COP21/CMP11) se celebró en París (Francia), desde el 30 de noviembre hasta el 11 de diciembre de 2015. Este importante encuentro fue organizado por la Convención Marco de las Naciones Unidas sobre el Cambio Climático (CMNUCC). Los esfuerzos realizados tenian como meta concluir un acuerdo mundial para reducir las emisiones de gases de efecto invernadero. La COP21 alcanzó en cierto modo su objetivo, definido por algunos como ambicioso e histórico. En efecto, al final de la reunión era general el consenso sobre la necesidad de actuar contra el calentamiento de la tierra. Se vio que es preciso combatir el cambio climático. Hay que actuar. Este es el gran logro del llamado Acuerdo de París, que fue aprobado y que se convertirá en jurídicamente vinculante si por lo menos 55 países que representen al menos el 55 por ciento de las emisiones globales de gases de efecto invernadero se adhieren a él a través de la firma seguida de su ratificación, aceptación, aprobación o adhesión. El acuerdo será aplicado a partir de 2020. Según el comité organizador, el resultado esperado era clave para limitar el calentamiento global por debajo de 2 grados centígrados en 2100, en comparación con el período anterior a la era industrial. Los investigadores de la ONU (Grupo Intergubernamental de Expertos sobre el Cambio Climático) acordaron en 2009 que esto era necesario para evitar catástrofes climáticas graves, y que ese resultado a su vez requeriría que las emisiones de gases de efecto invernadero se redujeran entre un 40 y un 70 por ciento en 2050 en comparación con el año 2010, alcanzando un nivel cero en 2100. Esta meta fue, no obstante, superada por el proyecto definitivo formalmente aceptado del Acuerdo de París que pretende también proseguir los esfuerzos para limitar el aumento de temperatura a 1,5 grados centígrados. Cf. P. de Charentenay, Luci e ombre sulla COP21: La Civiltà Cattolica 3976 (27 febbraio 2016) 363-372.

6 Sobre el acuerdo alcanzado en esta importante cumbre, se pronunció el Santo Padre en estos términos: "Se trata de un importante acuerdo, que representa un logro significativo para toda la Comunidad internacional y que pone de manifiesto una fuerte conciencia colectiva acerca de la grave responsabilidad que todos, individuos y naciones, tenemos en la protección de la creación, y en la promoción de una "cultura del cuidado que impregne toda la sociedad". Ahora es vital que los compromisos asumidos no solo representen un buen propósito, sino que todos los Estados sientan la obligación real de poner en marcha las acciones necesarias para salvaguardar nuestra amada Tierra, para bien de toda la humanidad, especialmente de las generaciones futuras": Francisco, Discurso al Cuerpo diplomático acreditado ante la Santa Sede (11 de enero de 2016): L'Osservatore Romano, ed. semanal en lengua española (15 enero 2016), p. 9. 
Plantar un árbol. En el centro de esta acción podemos entrever cómo el Sucesor del Apóstol Pedro no solamente se preocupa por cuestiones intraeclesiales. Casi me atrevería a decir que aquel día, plantando un árbol, el Papa estaba abriendo una espiral a la esperanza, parecía querer sostener a las nuevas generaciones con la misma ternura y constancia con que el labriego acompaña el crecimiento de la planta, con la misma paciencia.

Esperanza, acompañamiento y paciencia: da la impresión de que son tres quicios del servicio petrino de Francisco que pueden servirnos a nosotros de guía, talante y camino. Se trata de no sucumbir al gris mortecino, tan imperante por doquier; de no invadir, de no avasallar, de no imponer despóticamente, sino de acompasar nuestro ritmo al de quienes comparten con nosotros las cotidianas vicisitudes. Cuando muchos ceden ante prisas deletéreas, ante activismos enervantes, ante superficialidades dañinas, se vuelve urgente la pastoral de la paciencia, que nos asemeja a Dios, el sumo "paciente". Paciencia con nosotros mismos; paciencia con los demás. Es preciso en la hora presente entender la paciencia como ejercicio de un amor fuerte, de un amor que no se cansa. Qué urgente es hoy la paciencia del labrador; tendriamos que tener sed de paciencia en estos nuestros días, imbuidos de ligerezas.

Estas tres pistas seguramente están contenidas en este gesto del Obis po de Roma de plantar un árbol en medio del continente africano. Son invitaciones gestuales que piden ser captadas y comprendidas, llevadas a la práctica para que el torrente evangélico llegue por doquier. El Santo Padre quiere potenciar el abatimiento de muros y la apertura de ventanas al diálogo y el entendimiento mutuo. Francisco enseña con gestos y luminosas palabras, que primero las hace suyas para posteriormente proponerlas como luminarias a los agentes de pastoral en el despliegue de su actividad. Muchas de ellas han sido recogidas en su última encíclica, Laudato si', sobre el cuidado de la casa común, que ha suscitado interés más allá de los ambientes católicos.

Este documento subraya que la cuestión de la relación con la naturaleza pone a cada ser humano ante la responsabilidad de cuidar, de custodiar toda la creación y su belleza, con el fin de transmitir un mundo realmente habitable a las generaciones 
futuras. Para el Sumo Pontífice, cuidado de la persona y custodia del medio ambiente son coordenadas imbricadas, que se requieren y complementan ${ }^{7}$. Esta perspectiva, importante en el acervo de la sabiduría griega, muy radicada en la tradición cristiana y presente en el alma africana, fue subrayada en los discursos de Francisco durante su viaje a ese continente.

En efecto, señalaba el Obispo de Roma que estos valores están "profundamente arraigados en el alma africana". Y los reclama para nuestro mundo más desarrollado, un mundo que en lugar de proteger prefiere expoliar y explotar "nuestra casa común”, invitándolo a promover modelos de desarrollo sostenible y responsable. Así, Francisco insistía en África en una de las coordenadas de su encíclica: que hay "una clara relación entre la protección de la naturaleza y la construcción de un orden social justo y equitativo" y que, por tanto, la renovación de la relación con el medioambiente pasa por la renovación de la misma sociedad. Por eso es necesario combatir la pobreza, de la cual nace la desesperación que alimenta la violencia y el terrorismo ${ }^{8}$.

Os invito a mirar a Francisco regando esa plantita; os ruego que no paséis de largo ante ese árbol y aprendáis a conservar este gesto en vuestro interior y a extraer su significado como orientación de vida. Aquel pequeño arbolito plantado por el Santo Padre es un mensaje visual engarzado espléndidamente en el seno de la doctrina recogida anteriormente en la encíclica Laudato sí.

\section{- Abrir una puerta}

Un segundo gesto de Francisco ha recorrido el mundo entero. Por primera vez, el inicio celebrativo de un Jubileo de la Iglesia

\footnotetext{
Cf. M. López, El cuidado: un imperativo para la bioética, Universidad Pontificia de Comillas, Madrid 2011.

8 Cf. Francisco, Discurso en el encuentro con las autoridades de Kenia y el Cuerpo diplomático. State House. Nairobi (25 noviembre de 2015): L'Osservatore romano, ed. semanal en lengua española (27 de noviembre de 2015), p. 10; B. Stella, El cuidado del medio ambiente y el cuidado de la persona, en: F. Chica Arellano-C. Granados García (eds.), Loado seas, mi Señor. Comentario a la encíclica "Laudato si" del Papa Francisco, BAC, Madrid 2015, 39-45.
} 
católica no ha tenido lugar en Roma. El Sucesor de Pedro ha mostrado precisamente la catolicidad eclesial abriendo la Puerta Santa en la catedral en Bangui, que por unos momentos se convirtió en enclave de atención mundial. Ese evento fue resaltado por los medios de comunicación, que le otorgaron un significado especial, convirtiéndolo en una luz de una grandísima claridad y fuerza espiritual, a modo de un vivero de esperanza para la humanidad ${ }^{9}$.

No es extraño, por tanto, que esa iniciativa del Sumo Pontifice haya quedado en la retina y el corazón de muchos, así como en los anales de la historia. Era una simple puerta, discreta, extremamente simple, hecha en sencilla madera, lo que nos recuerda al carpintero de Nazaret. Por un día, la República Centroafricana, uno de los países más pobres, arrasados y conflictivos del planeta, dejó su puesto de ultimidad y fue un imán que polarizó la mirada y el corazón de innumerables multitudes de personas en el orbe entero.

En este marco sorprendente nos dejaria Francisco unas palabras que orientan este Jubileo de la misericordia: "Aquí, como en otras partes, muchos hombres y mujeres tienen sed de respeto, de justicia, de equidad, y no ven en el horizonte señales positivas. A ellos, Jesucristo viene a traerles el don de su justicia (cf. Jer 33,15). Viene a hacer fecundas nuestras historias personales y colectivas, nuestras esperanzas frustradas y nuestros deseos estériles. Y nos manda a anunciar, sobre todo a los oprimidos por los poderosos de este mundo, y también a los que sucumben bajo el peso de sus pecados [...]. Sí, Dios es Justicia. Por eso nosotros, cristianos, estamos llamados a ser en el mundo los artífices de una paz fundada en la justicia [...]. La salvación que se espera de Dios tiene también

9 "Bangui se convierte hoy en la capital espiritual del mundo. El Año Santo de la Misericordia llega anticipadamente a esta tierra. Una tierra que sufre desde hace años la guerra, el odio, la incomprensión, la falta de paz. En esta tierra sufriente también están todos los países del mundo que están pasando por la cruz de la guerra. Bangui se convierte en la capital espiritual de la oración por la misericordia del Padre. Pidamos todos nosotros paz, misericordia, reconciliación, perdón, amor. Pidamos la paz para Bangui, para toda la República Centroafricana para todos los países que sufren la guerra, pidamos la paz. Todos juntos pidamos amor y paz": Francisco, Palabras durante el rito de apertura de la Puerta Santa. Bangui (29 de noviembre de 2015): L'Osservatore Romano, ed. semanal en lengua española (4 de diciembre de 2015), p. 11. 
el sabor del amor [...]. Por todas partes, y sobre todo alli donde reina la violencia, el odio, la injusticia y la persecución, los cristianos estamos llamados a ser testigos de este Dios que es amor"10.

Notemos bien. El Obispo de Roma nos llama a ser testigos, no teóricos; testigos de un Dios que es amor. En la vida del discipulo de Cristo, la palabra tiene que hacerse gesto. Y el gesto ha de respaldar la palabra. Esto es clave en la vida cristiana. Esta sintonía y convergencia entre palabra y obra, esta ejemplaridad de vida deviene un programa completo para todos los miembros de la Iglesia. El "Año jubilar de la misericordia", oficialmente iniciado el pasado 8 de diciembre de 2015, celebración litúrgica de la entrañable fiesta de la Inmaculada Concepción y conmemoración de los 50 años de la clausura del Concilio Vaticano II, no desea ser sino prolongación de la hermosa tarea de ser testigos de la misericordia.

Esa afirmación de la homilía en la catedral de Bangui, una de las periferias geográficas más laceradas por la miseria, la guerra y la inequidad, venía a completarse con otra, donde el Pontífice reclamaba de todos los agentes de la evangelización que fueran "artesanos del perdón, especialistas de la reconciliación, expertos en misericordia" ${ }^{11}$. Estos incisos no pueden quedar sepultados por el olvido o la ignorancia.

Pocos días después de abrirse en Roma, en concreto, el 13 de diciembre 2015, tercer domingo de Adviento, se abría asimismo en nuestras catedrales la puerta de la misericordia, como un acicate para volver nuestra mirada a Cristo, "la única puerta" de la salvación de los hombres, como un impulso para sumarnos a ese río de misericordia que quiere el Papa que sea este Año Jubilar.

La suma de estas "dos puertas" de la única Iglesia es un incentivo pedagógico para adentrarnos en el significado de este Jubileo, que no puede convertirse solo en una búsqueda individual

10 Francisco, Homilia en la Santa Misa con sacerdotes, religiosos, religiosas, catequistas y jóvenes. Catedral de Bangui (29 noviembre de 2015): L'Osservatore Romano, ed. semanal en lengua española (4 de diciembre de 2015), pp. 10-11.

11 Ibid. 
de indulgencia, sin tener en cuenta la necesidad de ser indulgentes, misericordiosos con los hermanos más necesitados, en todas las dimensiones de la vida, contribuyendo a crear unos ámbitos más cargados de justicia y amor.

Recordemos bien: la convocatoria de este tiempo de copiosa gracia jubilar, con la promulgación de la Bula Misericordiae vultus (El rostro de la misericordia), es una invitación a mirar a Cristo, "rostro de la misericordia del Padre" (cf. MV 1) y, confortados con su mirada, dirigir nuestros ojos misericordiosos a los más necesitados, a los que Dios otorga su "primera misericordia" (cf. EG 198). A este respecto, leo un texto programático de la Bula de convocatoria del Jubileo: "Siempre tenemos necesidad de contemplar el misterio de la misericordia [...]. Misericordia: es la palabra que revela el misterio de la Santísima Trinidad. Misericordia: es el acto último y supremo con el cual Dios viene a nuestro encuentro. Misericordia: es la ley fundamental que habita en el corazón de cada persona cuando mira con ojos sinceros al hermano que encuentra en el camino de la vida. Misericordia: es la vía que une Dios y el hombre, porque abre el corazón a la esperanza de ser amados no obstante el limite de nuestro pecado" (MV 2).

El Sumo Pontífice reclama que esta gracia jubilar "haga más fuerte y eficaz el testimonio de los creyentes". Como he dicho, excluye desde el inicio una consideración meramente intimista del Jubileo que se olvide de la salida hacia el hermano para llevarle la gracia de la misericordia. El lema así lo resalta: "Misericordiosos como el Padre". Y solicita de la Iglesia que sea casa de misericordia: "La misericordia es la viga maestra que sostiene la vida de la Iglesia. Todo en su acción pastoral debería estar revestido por la ternura con la que se dirige a los creyentes: nada en su anuncio y en su testimonio hacia el mundo puede carecer de misericordia. La credibilidad de la Iglesia pasa a través del camino del amor misericordioso y compasivo. La Iglesia vive un deseo inagotable de brindar misericordia" (MV 10; cf. EG 21).

Esta enseñanza es hoy más que nunca actual y merece ser retomada en este Año Santo. Acojamos nuevamente sus palabras: "La Iglesia vive una vida auténtica cuando profesa y proclama la misericordia -el atributo más estupendo del Creador y del Redentor- 
y cuando acerca a los hombres a las fuentes de la misericordia del Salvador, de las que es depositaria y dispensadora" (MV 11).

\section{EVANGELII GAUDIUM Y LAUDATO SI’ EN EL "RÍO DE LA MISERICORDIA"}

La misericordia es una vena oculta que continuamente aflora en la lectura bíblica. Es la palabra más repetida en las oraciones de nuestra liturgia. Podemos leer toda la Historia de la Salvación, invocando como un coro continuo el salmo 136: "Porque es eterna su misericordia". Dice Francisco: "Repetir continuamente «Eterna es su misericordia", como lo hace el Salmo, parece un intento por romper el círculo del espacio y del tiempo para introducirlo todo en el misterio eterno del amor. Es como si se quisiera decir que no solo en la historia, sino por toda la eternidad el hombre estará siempre bajo la mirada misericordiosa del Padre. No es casual que el pueblo de Israel haya querido integrar este Salmo, el grande hallel como es conocido, en las fiestas litúrgicas más importantes" (MV 7).

El Magisterio de Francisco está vertebrado por este Salmo. Y en sus documentos aflora, como una corriente de vida, la experiencia de la misericordia, contemplando el Misterio de la Trinidad como su fuente y reclamando la exhortación del Maestro, "sed misericordiosos como el Padre", como norma de vida del discipulo. En este sentido, el tránsito entre la misericordia y los pobres se hace sin dificultad en la vida y magisterio del Santo Padre. Los desfavorecidos son aquellos que requieren de la misericordia en primer grado. No es extraño, pues, que la mirada especial hacia los más excluidos sea una referencia predominante en este pontificado ${ }^{12}$.

Fijémonos bien en un detalle: no es misericordia y pobreza, sino misericordiosos y pobres. El núcleo de la predicación evangélica no es para nada abstracto. Conlleva un carácter ejemplar, dinámico, concreto, práctico, existencial. El anuncio del Evangelio está llamado a incidir en la realidad. No puede restringirse a un mero

12 En esta exposición soy deudor de: A. Crespo Hidalgo, La misericordia entrañable de nuestro Dios, San Pablo, Madrid 2015. 
comunicado verbal. La Buena Noticia es una semilla reservada a clavarse con pujanza en una tierra concreta, en un corazón que la acoja. Recuerda el Papa, no solo con su pensamiento sino también con una vida gastada en ello, que los pobres, que tanto sufren la miseria, son los primeros destinatarios de la misericordia. Son ellos quienes antes abren su casa de par en par a Dios, cuyo corazón paterno late al ritmo de la misericordia ${ }^{13}$.

Estas verdades, que en este Jubileo alcanzan particular realce, las podemos constatar en dos de sus intervenciones más relevantes, después de Lumen fidei: la Exhortación apostólica Evangelii gaudium y la Carta encíclica Laudato si’. La preocupación de la Iglesia y del Santo Padre por los más desfavorecidos es un hilo transversal en esos dos documentos. Los marginados son los primeros destinatarios del anuncio evangelizador y los que más sufren el deterioro ambiental que hoy padece nuestro planeta ${ }^{14}$.

\subsection{Dios otorga a los pobres "su primera misericordia" (EG 198)}

Como he indicado, desde el inicio de su servicio a la Sede de Pedro, el Papa Francisco ha insistido en el lugar privilegiado que ocupan los menesterosos en la nueva evangelización. Desde esta atalaya hay que ver las reflexiones papales sobre el bien común y la armónica convivencia social, que podrá alcanzarse lanzando una llamada urgente a un diálogo social como camino para la consolidación de la paz en el mundo. Estos principios quedaron muy claros en su alocución a la Asamblea General de las Naciones Unidas $^{15}$ y en su reciente viaje a África ${ }^{16}$. Dos iniciativas que

13 Soy deudor de ideas anteriormente expuestas. Para ello véase: F. Chica Arellano, Dios otorga a los pobres "su primera misericordia". El Año jubilar de la misericordia ilumina las claves pastorales del Papa Francisco: Corintios XIII 157 (2016) 84-113.

14 Cf. J. Carrera, El problema ecológico: una cuestión de justicia, Cristianismo y Justicia, Barcelona 2009.

15 Cf. Francisco, Discurso ante la 70 Sesión de la Asamblea General de la Organización de las Naciones Unidas. Nueva York (25 de septiembre de 2015): L'Osservatore Romano, ed. semanal en lengua española (2 octubre 2015), p. 4-7.

16 Cf. Viaje del Papa Francisco a África (Kenia, Uganda y República Centroafricana) del 25 al 30 de noviembre de 2015. Cf. L'Osservatore Romano, ed. semanal en lengua española (27 noviembre 2015; 4 diciembre 2015). 
encierran un significado profundo que a la vez refleja el estilo pastoral de Francisco. El Obispo de Roma alza su voz profética y autorizada, en nombre de la Iglesia, ante los grandes exponentes de influencia de este mundo, representados en la Asamblea general de la Organización de las Naciones Unidas. Pero no olvida tocar en vivo, como pastor, la realidad más lacerante de la pobreza y la injusticia en el continente africano.

Estas mismas líneas de acción se hallaban ya contenidas en el número 198 de la Exhortación Evangelii gaudium. Ese número es texto orientativo fundamental: "Para la Iglesia la opción por los pobres es una categoría teológica antes que cultural, sociológica, política o filosófica. Dios les otorga "su primera misericordia". Esta preferencia divina tiene consecuencias en la vida de fe de todos los cristianos, llamados a tener "los mismos sentimientos de Jesucristo" (Flp 2,5). Inspirada en ella, la Iglesia hizo una opción por los pobres entendida como una "forma especial de primacia en el ejercicio de la caridad cristiana, de la cual da testimonio toda la tradición de la Iglesia». Esta opción -enseñaba Benedicto XVI- "está implícita en la fe cristológica en aquel Dios que se ha hecho pobre por nosotros, para enriquecernos con su pobreza". Por eso quiero una Iglesia pobre para los pobres. Ellos tienen mucho que enseñarnos. Además de participar del sensus fidei, en sus propios dolores conocen al Cristo sufriente. Es necesario que todos nos dejemos evangelizar por ellos. La nueva evangelización es una invitación a reconocer la fuerza salvífica de sus vidas y a ponerlos en el centro del camino de la Iglesia. Estamos llamados a descubrir a Cristo en ellos, a prestarles nuestra voz en sus causas, pero también a ser sus amigos, a escucharlos, a interpretarlos y a recoger la misteriosa sabiduría que Dios quiere comunicarnos a través de ellos" (EG 198).

Los pobres, por diversas razones, aparecen en un primer plano apenas la Iglesia deja que florezcan los frutos de su predicación. No es extraño, por tanto, que Evangelii gaudium, documento dedicado a la evangelización y repertorio de criterios del programa pastoral de Francisco, en su capitulo IV sobre "la dimensión social de la evangelización", subraye la correlación intrínseca entre confesión de fe y ejercicio práctico de la caridad: "Las enseñanzas de la Iglesia sobre situaciones contingentes están sujetas a mayores o nuevos desarrollos y pueden ser objeto de discusión, pero no podemos 
evitar ser concretos -sin pretender entrar en detalles- para que los grandes principios sociales no se queden en meras generalidades que no interpelan a nadie. Hace falta sacar sus consecuencias prácticas para que "puedan incidir eficazmente también en las complejas situaciones actuales" (EG 182).

Francisco, con estas palabras, no ha hecho otra cosa que traer a colación uno de los pilares básicos de la doctrina social de la Iglesia. No por otra cosa recuerda que los Pastores, acogiendo las aportaciones de las distintas ciencias, tienen derecho a emitir opiniones sobre todo aquello que afecte a la vida de las personas, ya que la tarea evangelizadora implica y exige una promoción integral de cada ser humano, en particular de los menesterosos. Y añade a este propósito: "Ya no se puede decir que la religión debe recluirse en el ámbito privado y que está solo para preparar las almas para el cielo. Sabemos que Dios quiere la felicidad de sus hijos también en esta tierra, aunque estén llamados a la plenitud eterna, porque Él creó todas las cosas "para que las disfrutemos" (1 Tm 6,17), para que todos puedan disfrutarlas. De ahí que la conversión cristiana exija revisar "especialmente todo lo que pertenece al orden social y a la obtención del bien común"” (EG 182).

\subsection{El bien común y "la opción preferencial por los pobres" (LS 158)}

Por la importancia que tienen en el caudal evangélico, el Santo Padre retoma estos temas e insiste en poner a los pobres en un primer plano en la Carta encíclica Laudato si', "sobre el cuidado de la casa común".

Para salir al encuentro de los menos favorecidos, hay que abandonar el individualismo caprichoso, el lujo, el derroche, en definitiva ese mercantilismo que asfixia al hombre en la búsqueda afanosa de la rentabilidad económica. Desde esta atalaya se comprende atinadamente el número 158 de Laudato si': "En las condiciones actuales de la sociedad mundial, donde hay tantas inequidades y cada vez son más las personas descartables, privadas de derechos humanos básicos, el principio del bien común se convierte inmediatamente, como lógica e ineludible consecuencia, 
en un llamado a la solidaridad y en una opción preferencial por los más pobres. Esta opción implica sacar las consecuencias del destino común de los bienes de la tierra, pero, como he intentado expresar en la Exhortación apostólica Evangelii gaudium, exige contemplar ante todo la inmensa dignidad del pobre a la luz de las más hondas convicciones creyentes. Basta mirar la realidad para entender que esta opción hoy es una exigencia ética fundamental para la realización efectiva del bien común" (LS 158) ${ }^{17}$.

El reciente documento de la Conferencia Episcopal Española, La Iglesia servidora de los pobres, ofrece una rica reflexión sobre esta misma problemática, con la riqueza del conocimiento más inmediato de la realidad concreta.

En este texto el episcopado reitera, una y otra vez, que para la Iglesia los pobres no son un estorbo, ni un fardo que hay que soportar con paciencia. Antes bien, el servicio a los pobres es el crisol por el que pasa la credibilidad eclesial. Los pequeños, los débiles, los que no cuentan, son la riqueza del pueblo de Dios. El servicio que a ellos se presta constituye el corazón de la misión eclesial. Por este motivo "es necesario "estar con los pobres" -hacer el camino con ellos- y no limitarnos a "dar a" los pobres recursos (alimento, ropa, etc.). El que acompaña se acerca al otro, toca el sufrimiento, comparte el dolor. "Los pobres, los abandonados, los enfermos, los marginados son la carne de Cristo". La cercanía es auténtica cuando nos afectan las penas del otro, cuando su desvalimiento y su congoja remueven nuestras entrañas y sufrimos con él. Ya no se trata solo de asistir y dar desde fuera, sino de participar en sus problemas y tratar de solucionarlos desde dentro. Por eso, si queremos ser compañeros de camino de los pobres, necesitamos que Dios nos toque el corazón; solo así seremos capaces de compartir cansancios y dolores, proyectos y esperanzas con la confianza de que no vamos solos, sino en compañia del Buen Pastor" ${ }^{18}$.

17 Cf. A. Bellocq Montano, El destino común de los bienes, en: F. Chica Arellano-C. Granados García (eds.), Loado seas, mi Señor. Comentario a la encíclica "Laudato si”' del Papa Francisco, BAC, Madrid 2015, 291-309.

18 Conferencia Episcopal Española, La Iglesia servidora de los pobres. Instrucción pastoral, 24 Abril 2015, n. 47. 


\section{LO QUE LE ESTÁ PASANDO A NUESTRA CASA COMÚN LO SUFREN ANTE TODO LOS POBRES}

Los pobres, los necesitados, los descartados de este mundo, no solamente son los primeros destinatarios de la misericordia. Son también quienes de una forma más cruda y ante todo padecen las inclemencias naturales, los desastres ambientales. Son los que más sufren los estragos provocados por los cambios climáticos ${ }^{19}$.

La gran aportación de la encíclica Laudato si' es que el Papa ha subrayado justamente esta vinculación, que en muchos casos había sido manipulada o sencillamente oscurecida. La custodia y salvaguardia del medio ambiente implica y conlleva una lucha infatigable contra la exclusión y la miseria (cf. LS 48-49) ${ }^{20}$. Y esto exige el cambio de mentalidad. Afrontar los retos socioeconómicos y medioambientales va a exigir una profunda transformación personal y colectiva, una real colaboración internacional, una auténtica "conversión ecológica", porque, como señala Francisco: "Vivir la vocación de ser protectores de la obra de Dios es parte esencial de una existencia virtuosa, no consiste en algo opcional ni en un aspecto secundario de la experiencia cristiana" (LS 217). Tampoco va a ser algo fácil para nuestras sociedades; por eso la encíclica conjuga en clave cristiana la cuestión del cambio social y la conversión personal y espiritual para este nuevo tiempo. De ahí el valor de Laudato si' como texto de referencia de la interpretación católica de las relaciones sociales y medioambientales en el siglo XXI; y también como declaración de apoyo público al esfuerzo de las negociaciones y de los procesos internacionales de diálogo en torno a estas cuestiones ${ }^{21}$. Cuando el Obispo de Roma, al comienzo de Laudato si', expresa que

19 Cf. J. M. Caamaño López, La encíclica Laudato si’ y la teología moral, en: E. Sanz Giménez-Rico (ed.), Cuidar de la Tierra, cuidar de los pobres. Laudato si' desde la teología y con la ciencia. Sal Terrae, Maliaño 2015, 161-168.

20 Cf. J. L. Martínez, Laudato si' y la cuestión medioambiental. Clamor de la Tierra y de los pobres, en: E. Sanz Giménez-Rico (ed.), Cuidar de la Tierra, cuidar de los pobres. Laudato si desde la teología y con la ciencia. Sal Terrae, Maliaño 2015, 23-49.

21 Cf. J. Ignacio García Jiménez, El diálogo en Laudato si'. Pasión por responder a los retos medioambientales y sociales, en: E. Sanz Giménez-Rico (ed.), Cuidar de la Tierra, cuidar de los pobres. Laudato si' desde la teología y con la ciencia. Sal Terrae, Maliaño 2015, 126-127. 
"frente al deterioro ambiental global, quiero dirigirme a cada persona que habita este planeta [...] y que intento especialmente entrar en diálogo con todos acerca de nuestra casa común" (LS 3), no hace otra cosa que mostrar su aspiración a participar en un debate público de enorme importancia y actualidad. Y efectivamente así lo hizo, pues Francisco ciertamente publicó su encíclica con suficiente antelación como para que su contenido pudiera formar parte de las discusiones previas a la susodicha Conferencia de París sobre el cambio climático.

Es preciso reiterar, por consiguiente, que, si durante tiempo la ecologia, la economía y la sociología han caminado cada una por su cuenta, en una fragmentariedad querida por muchos, el gran mérito de Laudato si' ha sido haber evidenciado el estrecho vínculo existente entre cuestiones sociales y humanas y cuestiones ambientales: "Hoy el análisis de los problemas ambientales es inseparable del análisis de los contextos humanos, familiares, laborales, urbanos [...] de la relación de cada persona consigo mismo" (LS 141). Por ello, es "fundamental buscar soluciones integrales que consideren las interacciones de los sistemas naturales entre si y con los sistemas sociales. No hay dos crisis separadas, una ambiental y otra social, sino una sola y compleja crisis socio-ambiental" (LS 139). Veamos sus efectos y raíces.

\section{LOS EFECTOS DEL PROBLEMA ECOLÓGICO}

Laudato si'se ha convertido en un fenómeno mediático. Jamás un texto pontificio ha tenido tanta irradiación en medios internacionales, en debates universitarios, en declaraciones públicas, en ambientes académicos. Sin embargo, esta encíclica no es un tratado sociológico, no es un manual "verde". Más bien, es un documento eclesial, magisterial, que no puede analizarse aisladamente. Solo se entiende sumergida en el cauce de la doctrina social de la Iglesia, a la luz del pensamiento papal que la ha preparado (cf. LS 3-6) ${ }^{22}$.

En su cap. I, Francisco enumera los efectos de esta crisis socioambiental (cf. LS 17-61).

22 Cf. G. del Pozo Abejón, El evangelio de la creación, en: F. Chica Arellano-C. Granados García (eds.), Loado seas, mi Señor. Comentario a la encíclica "Laudato si'” del Papa Francisco, BAC, Madrid 2015, 184-185. 


\subsection{Contaminación, cambio climático y la "cultura del descarte"}

Lo primero que se observa, apenas se reflexiona en serio y no se tergiversa la realidad, es la contaminación que nos rodea. A este propósito dice la encíclica: "Existen formas de contaminación que afectan cotidianamente a las personas. La exposición a los contaminantes atmosféricos produce un amplio espectro de efectos sobre la salud, especialmente de los más pobres, provocando millones de muertes prematuras [...]. Hay que considerar también la contaminación producida por los residuos, incluyendo los desechos peligrosos presentes en distintos ambientes. Se producen cientos de millones de toneladas de residuos por año, muchos de ellos no biodegradables: residuos domiciliarios y comerciales, residuos de demolición, residuos clínicos, electrónicos e industriales, residuos altamente tóxicos y radioactivos. La tierra, nuestra casa, parece convertirse cada vez más en un inmenso depósito de porquería [...]. Estos problemas están íntimamente ligados a la cultura del descarte, que afecta tanto a los seres humanos excluidos como a las cosas que rápidamente se convierten en basura" (LS 20-22) ${ }^{23}$.

Luego, el Sumo Pontífice señala una cuestión que está volviéndose peliaguda. Me refiero a la escasez y mala calidad del agua potable: "Mientras se deteriora constantemente la calidad del agua disponible, en algunos lugares avanza la tendencia a privatizar este recurso escaso, convertido en mercancía que se regula por las leyes del mercado. En realidad, el acceso al agua potable y segura es un derecho humano básico, fundamental y universal, porque determina la sobrevivencia de las personas, y por lo tanto es condición para el ejercicio de los demás derechos humanos" (LS 30).

Puntualiza después el Obispo de Roma un tema realmente candente: la pérdida de biodiversidad: "Cada año desaparecen miles de especies vegetales y animales que ya no podremos conocer, que nuestros hijos ya no podrán ver, perdidas para siempre. La

${ }^{23}$ Cf. P. Linares Llamas-J.C. Romero Mora, Laudato si y la ciencia, en: E. Sanz Giménez-Rico (ed.), Cuidar de la Tierra, cuidar de los pobres. Laudato si' desde la teología y con la ciencia. Sal Terrae, Maliaño 2015, 114-115. 
inmensa mayoria se extinguen por razones que tienen que ver con alguna acción humana. Por nuestra causa, miles de especies ya no darán gloria a Dios con su existencia ni podrán comunicarnos su propio mensaje. No tenemos derecho" (LS 33).

\subsection{Deterioro de la calidad de vida}

Contaminación, falta de agua y pérdida de biodiversidad dan como resultado el menoscabo de la calidad de vida: "Si tenemos en cuenta que el ser humano también es una criatura de este mundo, que tiene derecho a vivir y a ser feliz, y que además tiene una dignidad especialísima, no podemos dejar de considerar los efectos de la degradación ambiental, del actual modelo de desarrollo y de la cultura del descarte en la vida de las personas" (LS 43) ${ }^{24}$.

24 A este respecto no podemos dejar de traer a colación unas recientes palabras del Papa: "También hoy como entonces, escuchamos la voz de Jacob que dice a sus hijos: "Bajad y comprad alli [el grano] para nosotros, a fin de que sobrevivamos y no muramos" (Gn 42, 2). Es la voz de los que escapan de la miseria extrema, al no poder alimentar a sus familias ni tener acceso a la atención médica y a la educación, de la degradación, porque no tienen ninguna perspectiva de progreso, o de los cambios climáticos y las condiciones climáticas extremas. Todos saben que el hambre sigue siendo, desgraciadamente, una de las plagas más graves de nuestro mundo, con millones de niños que mueren cada año por su causa. Duele constatar, sin embargo, que a menudo estos emigrantes no entran en los sistemas internacionales de protección en virtud de los acuerdos internacionales. ¿Cómo no ver en todo esto el fruto de una "cultura del descarte" que pone en peligro a la persona humana, sacrificando a hombres y mujeres a los ídolos del beneficio y del consumismo? Es grave acostumbrarse a estas situaciones de pobreza y necesidad, al drama de tantas personas, y considerarlas como "normales". No se considera ya a las personas como un valor primario que hay que respetar y amparar, especialmente si son pobres o discapacitadas, si "todavía no son útiles" -como los no nacidos- , o si "ya no sirven "-como los ancianos-. Nos hemos hecho insensibles a cualquier forma de despilfarro, comenzando por el de los alimentos, que es uno de los más vergonzosos, pues son muchas las personas y las familias que sufren hambre y desnutrición [...]. Se hace necesario un compromiso común que acabe decididamente con la cultura del descarte y de la ofensa a la vida humana, de modo que nadie se sienta descuidado u olvidado, y que no se sacrifiquen más vidas por falta de recursos y, sobre todo, de voluntad política": Francisco, Discurso al Cuerpo diplomático acreditado ante la Santa Sede (11 de enero de 2016): L'Osservatore Romano, ed. semanal en lengua española (15 enero 2016), p. 7. 
Con un realismo crudo reflexiona Francisco sobre lo imposible que resulta para muchos vivir en las grandes ciudades, con el consiguiente deterioro de las relaciones sociolaborales. En este contexto, Su Santidad se detiene en algo que está dañando incisivamente a nuestra convivencia. Se trata del mal uso de los nuevos sistemas de comunicación. Cuando las dinámicas de los medios del mundo digital se convierten en omnipresentes, no favorecen el desarrollo de una capacidad de vivir sabiamente, ni de pensar en profundidad, ni de amar con generosidad. Y alienta a que esos medios se traduzcan "en un nuevo desarrollo cultural de la humanidad y no en un deterioro de su riqueza más profunda. La verdadera sabiduría, producto de la reflexión, del diálogo y del encuentro generoso entre las personas, no se consigue con una mera acumulación de datos que termina saturando y obnubilando, en una especie de contaminación mental. Al mismo tiempo, tienden a reemplazarse las relaciones reales con los demás, con todos los desafios que implican, por un tipo de comunicación mediada por Internet. Esto permite seleccionar o eliminar las relaciones según nuestro arbitrio, y así suele generarse un nuevo tipo de emociones artificiales, que tienen que ver más con dispositivos y pantallas que con las personas y la naturaleza. Los medios actuales permiten que nos comuniquemos y que compartamos conocimientos y afectos. Sin embargo, a veces también nos impiden tomar contacto directo con la angustia, con el temblor, con la alegría del otro y con la complejidad de su experiencia personal. Por eso no debería llamar la atención que, junto con la abrumadora oferta de estos productos, se desarrolle una profunda y melancólica insatisfacción en las relaciones interpersonales, o un dañino aislamiento" (LS 47).

Son cuestiones muy concretas, abordadas con claridad meridiana por el Papa, que se suma de este modo a otros análisis y resultados suministrados por instituciones y ONG'S sensibles a estos problemas. Desde varias vertientes cada día se reclama más a la política oficial que tenga en cuenta en sus programas el cuidado del medio ambiente como una forma esencial del cuidado de las mismas personas ${ }^{25}$.

25 Cf. Ll. Oviedo Torró-A. Garre Garre, Cuidado por la tierra, atención a la persona, en: F. Chica Arellano-C. Granados García (eds.), Loado seas, mi Señor. Comentario a la encíclica "Laudato si”" del Papa Francisco, BAC, Madrid 2015, 275-290. 


\section{EN LAS RAÍCES DEL PROBLEMA}

La encíclica aporta una rica novedad cuando aborda las causas del problema ecológico, sobre todo al incidir en la raíz humana del mismo. De esto trata Francisco en el capitulo tercero de Laudato si'. Señala Francisco a este respecto: "No nos servirá describir los sintomas, si no reconocemos la raíz humana de la crisis ecológica. Hay un modo de entender la vida y la acción humana que se ha desviado y que contradice la realidad hasta dañarla” (LS 101).

Muchos de los males que sufre el planeta se deben, a juicio del Pontifice, a que hemos crecido pensando que éramos propietarios y dominadores de la Tierra, autorizados a expoliarla: "Es cierto que existen causas que exceden en gran medida la responsabilidad humana en el deterioro de la naturaleza y que la propia encíclica reconoce (n. 23); pero también parece una evidencia el hecho de que la responsabilidad humana si tiene, sin embargo, un papel relevante en esa degradación que sufre el conjunto de la Tierra. Por eso el Papa, además de señalar algunos sintomas más o menos discutibles, afirma la necesidad de reconocer también "la raíz humana de la crisis ecológica", dado que hay "un modo de entender la vida y la acción humana que se ha desviado y la contradice hasta dañarla» [...] (n. 101)"26.

El Obispo de Roma denuncia esta situación pero abre pautas de solución, que también tienen su raíz en una vuelta a contemplar la grandeza de la creación y la responsabilidad del ser humano, como criatura, responsable de su conservación. Leamos desde esta perspectiva este número de la encíclica: "Se tiende a creer "que todo incremento del poder constituye sin más un progreso, un aumento de seguridad, de utilidad, de bienestar, de energía vital, de plenitud de los valores", como si la realidad, el bien y la verdad brotaran espontáneamente del mismo poder tecnológico y económico. El hecho es que "el hombre moderno no está preparado para utilizar el poder con acierto", porque el inmenso crecimiento

26 J. M. Caamaño López, La encíclica Laudato si` y la teología moral, en: E. Sanz Giménez-Rico (ed.), Cuidar de la Tierra, cuidar de los pobres. Laudato sí desde la teología y con la ciencia. Sal Terrae, Maliaño 2015, 144. 
tecnológico no estuvo acompañado de un desarrollo del ser humano en responsabilidad, valores y conciencia.

Cada época tiende a desarrollar una escasa autoconciencia de sus propios límites. Por eso es posible que hoy la humanidad no advierta la seriedad de los desafios que se presentan, $\mathrm{y}$ "la posibilidad de que el hombre utilice mal el poder crece constantemente" cuando no está "sometido a norma alguna reguladora de la libertad, sino únicamente a los supuestos imperativos de la utilidad y de la seguridad". Su libertad se enferma cuando se entrega a las fuerzas ciegas del inconsciente, de las necesidades inmediatas, del egoísmo, de la violencia. En ese sentido, está desnudo y expuesto frente a su propio poder, que sigue creciendo, sin tener los elementos para controlarlo. Puede disponer de mecanismos superficiales, pero podemos sostener que le falta una ética sólida, una cultura y una espiritualidad que realmente lo limiten y lo contengan en una lúcida abnegación” (LS 105).

Esto pone de relieve una gran verdad, a menudo arrinconada cuando no postergada voluntariamente, que la doctrina social de la Iglesia sostiene sin paliativos: $\mathrm{El}$ ser humano no es plenamente autónomo. El haber pensado y sostenido lo contrario ha llevado a resultados nocivos que han afectado negativamente al entorno medioambiental: "Una visión del hombre y de las cosas desligada de toda referencia a la transcendencia ha llevado a rechazar el concepto de creación y a atribuir al hombre y a la naturaleza una existencia completamente autónoma. El vínculo que une el mundo con Dios ha sido roto: esta ruptura ha acabado desvinculando también al hombre de la tierra y, más radicalmente, ha empobrecido su misma identidad. El ser humano ha llegado a considerarse extraño al contexto ambiental en el que vive" 27 . Por este motivo ya reclamaba Juan Pablo II, en su encíclica Centesimus annus, "la necesidad de dar mayor relieve a la profunda conexión que hay entre una ecología medio ambiental y una ecología humana"28. Estas palabras, refrendadas por Francisco, muestran la necesidad de promover

27 Cf. Pontificio Consejo "Justicia y Paz", Compendio de la doctrina social de la Iglesia. BAC, Madrid 2005, 237.

28 Juan Pablo II, Centesimus annus, 38. 
una mejor educación ética y moral y un mejor conocimiento de la doctrina social de la Iglesia para afrontar la degradación ambiental existente y salvaguardar la vida en nuestro planeta.

A este propósito, podemos encontrar apoyo en un instrumento muy valioso, del que creo que no se han extraído todas sus posibilidades catequéticas y formativas. Me refiero al Compendio de la Doctrina social de la Iglesia ${ }^{29}$, promovido por el Pontificio Consejo "Justicia y Paz", y publicado en el 2005. En concreto, el capítulo $\mathrm{X}$, titulado "Salvaguardar el medio ambiente", está en la base de la reflexión de Francisco. Y la Tercera Parte, "Doctrina Social y acción eclesial" es un foco iluminador para la acción pastoral y, en concreto, para el compromiso de nuestros fieles laicos. La rica reflexión de la Iglesia sobre estos temas es un servicio profético a esta sociedad actual que reclama luces orientadoras en estos momentos de cierta crisis de pensamiento y de dirección.

El Magisterio de la Iglesia ha reclamado la necesidad de encontrar una traducción adecuada en el ámbito jurídico de la responsabilidad común de cuidar la naturaleza: "Es importante que la comunidad internacional elabore reglas uniformes, de manera que esta reglamentación permita a los Estados controlar más eficazmente las diversas actividades que determinan efectos negativos sobre el ambiente y preservar los ecosistemas, previniendo posibles incidentes" ${ }^{\prime 30}$.

\section{UNAS CLAVES PEDAGÓGICAS: EDUCACIÓN Y ESPIRITUALIDAD ECOLÓGICA}

Los capítulos IV y V de la encíclica marcan una serie de pautas más operativas. Estas tienen un horizonte desde el que deben verse estas líneas de acción. Es su capítulo II. En él, el Papa nos invita a releer el Evangelio de la creación, a adentrarnos en el misterio de las cosas: "Las criaturas de este mundo no pueden ser consideradas un bien sin dueño: "Son tuyas, Señor, que amas la vida" (Sb 11,26).

29 Pontificio Consejo "Justicia y Paz", Compendio de la doctrina social de la Iglesia, BAC, Madrid 2005.

30 Ibid., 239. 
Esto provoca la convicción de que, siendo creados por el mismo Padre, todos los seres del universo estamos unidos por lazos invisibles y conformamos una especie de familia universal, una sublime comunión que nos mueve a un respeto sagrado, cariñoso y humilde. Quiero recordar que "Dios nos ha unido tan estrechamente al mundo que nos rodea, que la desertificación del suelo es como una enfermedad para cada uno, y podemos lamentar la extinción de una especie como si fuera una mutilación"” (LS 89) ${ }^{31}$.

"La teologia de la creación esbozada en Laudato si' no es, pues, ni debe ser en ningún caso, una reflexión abstracta sobre no se sabe qué cosas sin interés ni traducción práctica. Antes bien, al contrario: ofrece y debe ofrecer la visión evangélica, la mirada crítica y la palabra oportuna que, enraizada en la contemplación del misterio de Dios y de su revelación en Jesucristo, establece las prioridades sociales según el orden del Reino y no según la lógica de la sociedad tecnocrática y liberal. La teología de la creación tiene, pues, en sus mismas raíces, así lo subraya el Papa, un fuerte componente ético que nos hace ver la injusticia de la realidad con los ojos proféticos de quien no la tolera y, al mismo tiempo, nos infunde esperanza en la actuación de Dios, que la sustenta y acompaña desde su inicio hasta su fin. En esta dimensión ética que busca la igualdad y el bien general, especialmente de los pobres, nos encontramos creyentes e increyentes, pues como dice Francisco: todos "estamos de acuerdo en que la Tierra es esencialmente una herencia común, cuyos frutos deben beneficiar a todos" (LS 93)"32.

Sentadas estas bases, en el capítulo VI de Laudato si', el Santo Padre reflexiona sobre unas claves pedagógicas y líneas de espiritualidad muy sugerentes para motivar el cuidado de nuestra casa común. Esta tarea requiere un lento itinerario de educación, una seria formación de las conciencias y hasta una nueva forma de espiritualidad. El Papa sugiere algunos compromisos en los que habria que insistir ya desde ahora.

31 Cf. Francisco, Evangelii gaudium, 105.

32 P. Castelao, La "cuestión ecológica" y la teología de la creación, en: E. Sanz Giménez-Rico (ed.), Cuidar de la Tierra, cuidar de los pobres. Laudato sí desde la teología y con la ciencia, Sal Terrae, Maliaño 2015, 69-70. 


\subsection{Algunos principios pedagógicos, a la luz del "Evangelio de la creación"}

Desde esta perspectiva global del Evangelio de la creación, el Papa Francisco concretiza una serie de indicaciones pedagógicas:

- Para comenzar, no se puede identificar la libertad con el deseo de consumir. A este respecto, señala Francisco que "mientras más vacío está el corazón de la persona, más necesita objetos para comprar, poseer y consumir" (LS 204). Esto pone de manifiesto algo inquietante: "Tenemos demasiados medios para unos escasos y raquíticos fines" (LS 203). Para afrontar este déficit, conviene resaltar la necesidad de desempolvar una vena muy rica de nuestra mejor espiritualidad, hoy no muy al uso: la ascesis. El Evangelio es siempre una cierta "voz discordante" cuando se enfrenta a los poderes de este mundo: ante el consumo compulsivo y el egoísmo en la adquisición de los bienes, conviene hablar hoy de austeridad, de ascesis cristiana: "La sobriedad que se vive con libertad y conciencia es liberadora. No es menos vida, no es una baja intensidad, sino todo lo contrario. En realidad, quienes disfrutan más y viven mejor cada momento son los que dejan de picotear aquí y allá, buscando siempre lo que no tienen, y experimentan lo que es valorar cada persona y cada cosa, aprenden a tomar contacto y saben gozar con lo más simple. Así son capaces de disminuir las necesidades insatisfechas y reducen el cansancio y la obsesión. Se puede necesitar poco y vivir mucho, sobre todo cuando se es capaz de desarrollar otros placeres y se encuentra satisfacción en los encuentros fraternos, en el servicio, en el despliegue de los carismas, en la música y el arte, en el contacto con la naturaleza, en la oración. La felicidad requiere saber limitar algunas necesidades que nos atontan, quedando así disponibles para las múltiples posibilidades que ofrece la vida" (LS 223).

- Es el momento de revisar los mitos de la modernidad: el individualismo, el progreso indefinido ${ }^{33}$, la competencia, el consumismo, el mercado sin reglas. Y recuperar un equilibrio

33 Cf. Pontificio Consejo "Justicia y Paz", Compendio de la doctrina social de la Iglesia, BAC, Madrid 2005, 234-235. 
integral, es decir, interno, solidario, natural y espiritual (cf. LS 210). El homo oeconomicus no puede ser el paradigma en el que se agote la honda riqueza del ser humano, criatura de Dios, creado a su imagen y semejanza.

- Hoy es básico evidenciar una sugerencia del Santo Padre: "Un cambio en los estilos de vida podría llegar a ejercer una sana presión sobre los que tienen poder político, económico y social. Es lo que ocurre cuando los movimientos de consumidores logran que dejen de adquirirse ciertos productos y así se vuelven efectivos para modificar el comportamiento de las empresas" (LS 206).

- Y concreta el Papa: "Es muy noble asumir el deber de cuidar la creación con pequeñas acciones cotidianas, y es maravilloso que la educación sea capaz de motivarlas hasta conformar un estilo de vida", que el Papa resume en gestos muy concretos (LS 211).

\subsection{La contribución de la espiritualidad cristiana: "conversión ecológica"}

Francisco reclama con insistencia: Una verdadera conversión ecológica nos llevaría a vivir "la vocación de ser protectores de la obra de Dios" (LS 217). Y lo expresa de esta manera: "Si "los desiertos exteriores se multiplican en el mundo porque se han extendido los desiertos interiores", la crisis ecológica es un llamado a una profunda conversión interior. Pero también tenemos que reconocer que algunos cristianos comprometidos y orantes, bajo una excusa de realismo y pragmatismo, suelen burlarse de las preocupaciones por el medio ambiente. Otros son pasivos, no se deciden a cambiar sus hábitos y se vuelven incoherentes. Les hace falta entonces una conversión ecológica, que implica dejar brotar todas las consecuencias de su encuentro con Jesucristo en las relaciones con el mundo que los rodea" (LS 217). Para ello es necesario cultivar la gratitud y la gratuidad, la comunión universal, el entusiasmo de la creatividad y la responsabilidad que brota de la fe (cf. LS 220) ${ }^{34}$.

34 Cf. P.K.A. Turkson, La conversión ecológica, en: F. Chica Arellano-C. Granados García (eds.), Loado seas, mi Señor. Comentario a la encíclica "Laudato si" del Papa Francisco, BAC, Madrid 2015, 21-38. 
El Papa subraya el aporte que puede hacer la espiritualidad cristiana para la regeneración ecológica: el mejor espíritu cristiano implica sobriedad y simplicidad y evita la dinámica del dominio y la mera acumulación de placeres (cf. LS 222). Implica también capacidad de convivencia y de comunión, que nos lleva a vivir la fraternidad universal (cf. LS 228), la superación de la violencia y la construcción de una "civilización del amor", propuesta ya por Pablo VI (cf. LS 231).

Toda la naturaleza nos habla de Dios, como canta San Juan de la Cruz (cf. LS 234). Y hace una hermosa descripción de cómo diversos elementos de la naturaleza -como el agua, el vino, la cera o el aceite- han llegado a entrar en el ámbito de los signos sacramentales (cf. LS 235).

La fe cristiana nos invita a celebrar el descanso dominical como contemplación de la creación (cf. LS 237). La recuperación del domingo como día del Señor, día de descanso, día de la familia, es una clave de identificación cristiana esencial en medio de esta cultura multiétnica y multirreligiosa en la que vivimos.

Es más, nos lleva también a ver a la Trinidad como modelo de las relaciones de las personas con los demás y con todas las criaturas (cf. LS 238-240). Para los cristianos creer en un solo Dios que es comunión trinitaria lleva a pensar que toda la realidad contiene en su seno una marca propiamente trinitaria. Su contemplación "nos invita a madurar una espiritualidad de la solidaridad global que brota del misterio de la Trinidad" (LS 240) ${ }^{35}$.

Deseo ofrecer una última consideración. Me sirvo para ello de las palabras de los miembros de la Conferencia Episcopal Española en un reciente documento: "Recordamos frecuentemente con el Papa Francisco que "el tiempo es superior al espacio" (cf. EG 222). "Este principio permite trabajar a largo plazo sin obsesionarse por resultados inmediatos. Ayuda a soportar con paciencia las

35 Cf. B. Daelemans, Contemplar, celebrar, cuidar. Revisitar la sacramentalidad del mundo, en: E. Sanz Giménez-Rico (ed.), Cuidar de la Tierra, cuidar de los pobres. Laudato sí desde la teología y con la ciencia, Sal Terrae, Maliaño 2015, 87-103. 
situaciones dificiles y adversas [...]. Darle prioridad al espacio lleva a enloquecerse para tener todo resuelto en el presente [...]. Darle prioridad al tiempo es ocuparse de iniciar procesos más que de poseer espacios" (cf. Ibíd. 223). Por eso, no nos quedemos en lo inmediato, en los limitados espacios sociales en que nos movemos, en lo que logramos aquí y ahora. Demos prioridad a los procesos que abren horizontes nuevos y promovamos acciones significativas que hagan patente la presencia ya entre nosotros del Reino de Dios que se consumará en la vida eterna" ${ }^{36}$.

\section{CONCLUSIÓN: “ALABADO SEAS, MI SEÑOR”}

Terminamos nuestra reflexión recurriendo al himno de san Francisco de Asís, que inspiró el título de esta encíclica: Laudato si'. Dice el Santo Padre: "Cuando tomamos conciencia del reflejo de Dios que hay en todo lo que existe, el corazón experimenta el deseo de adorar al Señor por todas sus criaturas y junto con ellas, como se expresa en el precioso himno de san Francisco de Asís:

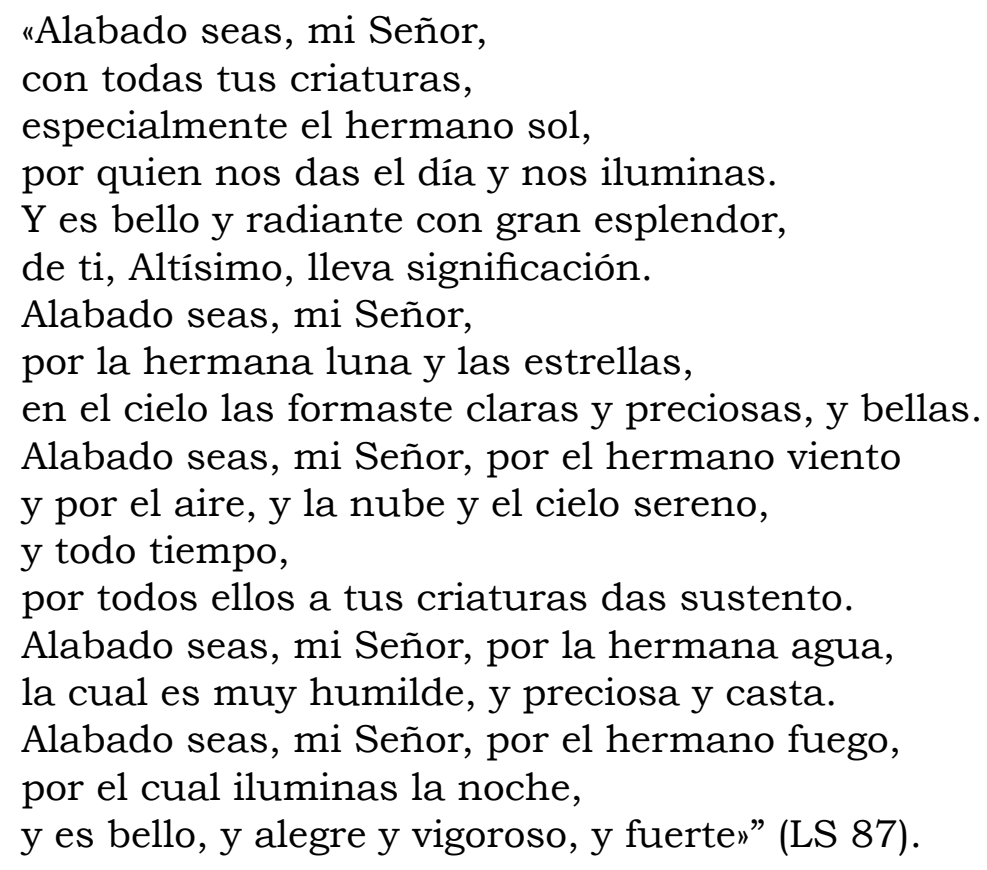

36 Conferencia Episcopal Española, La Iglesia servidora de los pobres, 24 Abril 2015, n. 58. 